\title{
External Monitoring and Dynamic Behavior in Mutual Funds
}

\author{
Jian Wang, ${ }^{1}$ Xiaoting Wang, ${ }^{2}$ Xintian Zhuang, ${ }^{1}$ and Jiliang Sheng ${ }^{3}$ \\ ${ }^{1}$ School of Business Administration, Northeastern University, Shenyang 110819, China \\ ${ }^{2}$ Department of Economics, Acadia University, Wolfville, NS, Canada B4P 2R6 \\ ${ }^{3}$ School of Statistics, Jiangxi University of Finance and Economics, Nanchang 330013, China
}

Correspondence should be addressed to Xiaoting Wang; xiaoting.wang@acadiau.ca

Received 9 March 2016; Accepted 5 June 2016

Academic Editor: Xiaodong Lin

Copyright (C) 2016 Jian Wang et al. This is an open access article distributed under the Creative Commons Attribution License, which permits unrestricted use, distribution, and reproduction in any medium, provided the original work is properly cited.

\begin{abstract}
This paper studies the impact of external monitoring on the behavior in mutual funds. Specifically, we investigate how and why external monitoring can alleviate contracting inefficiency caused by information asymmetry between investors and the manager. It is shown that efficiency loss emerges when investors contract with the manager just relying on her investment return history. The establishment of external monitoring that provides investors more information about the manager's ability can improve contracting efficiency, which converges to first-best as external monitoring strengthens. These results provide strong support for tightening supervision in mutual fund industry.
\end{abstract}

\section{Introduction}

In 2014 there are approximately 80,000 mutual funds worldwide with more than US $\$ 31$ trillion of assets under management. In the United States alone more than 9,200 mutual funds manage almost $\$ 16$ trillion worth of investment. As a popular investment instrument for households and institutional investors, open-end funds have the advantage of sharing risks and benefits among investors and management. However, adverse selection problem arises due to the separation of fund ownership and management because of incomplete and asymmetric information. Therefore, the issue of generating incentives to align the interests has become a main focus of research on open-end fund management.

Incentive contracts are considered to be an effective mechanism to reduce the adverse selection problem of fund managers. In fierce competition with other mutual funds in the market, fund performance (absolute or relative) sends a strong signal to investors regarding the quality of the fund, that is, the hidden information about the capability of the fund managers. According to the relative performance, investors can either increase or decrease their investment allocation in the mutual funds, which consequently affects the compensation of fund managers. Empirical studies on flowperformance relationship show strong positive correlation between money flow and past performance of funds. Fund performance has been the most critical factor for investors' decision making.

Ippolito [1] observes that mutual funds with higher past returns tend to attract more new money in the following year. Evidence that investor cash flows "chase" recent high returns is also provided by, among many others, Chevalier and Ellison [2] and Sirri and Tufano [3]. Del Guercio and Tkac [4] find that mutual fund investors, when directing new money flows, pay more attention to simple measures of relative return than to more complex measures such as alpha. However, while the mutual fund industry constantly competes for cash flows, in the short run it is difficult to draw conclusion on fund managers' true ability and the investment value of funds. Daniel et al. [5] show that many funds including star funds are not persistent in their performance over the short run. Through their empirical work on large samples of mutual funds, Elton et al. [6], Elton et al. [7], and Gruber [8] also demonstrate that fund performance is not persistent. Based on these studies, it is evident that performancebased incentive contracts cannot solve the adverse selection problem completely and hence cannot serve as a good device to eliminate incompetent managers while keeping the capable ones. For the lack of persistence in fund performance in the short run, performance-based fees will not only frustrate 
skilled managers but also bring inefficiency to the financial market and hurt investors' interest.

This paper studies the impact of external monitoring on the behavior in mutual funds in a framework similar to Gervais et al. [9], who show that fund families as delegated monitors can credibly reveal information about managerial skill to investors via boosting the reliability of its retentions through the firing of others. Different from their study, this paper explores how and why external monitoring can alleviate contracting inefficiency that results from investors just chasing the manager's investment performance. In delegated investment markets investors (especially individuals) often chase "hot" funds with impressive recent returns. Many investors do not have the time or expertise to evaluate the quality of fund management. In this study, we assume that external monitoring can provide investors with some (but not necessarily complete or accurate) information on whether a manager's performance is due to her ability or luck. We show that the inclusion of external monitoring can improve contracting efficiency, which converges to first-best as external monitoring strengthens in the dynamical system. Our result suggests that it is essential and beneficial to tighten supervision in mutual fund industry.

External monitoring can come from at least two sources. From a regulatory perspective, in almost all jurisdictions investment vehicles such as mutual funds that deal with general public are required to file certain documentations and disclose relevant information to the public on a regular basis. Required information usually includes some background information of fund managers such as education or other qualifications and past experiences. On quarterly, semiannual, and annual basis, funds are required to disclose their top holdings (or complete list of holdings in some jurisdictions such as China) in stocks. Compliance with such regulations provides investors with a certain degree of transparency on fund operations. On the other hand, external monitoring also comes from independent specialized agencies or organizations, with Morningstar and Lipper as the most noticeable examples. Such agencies are devoted to providing relevant commentary and assessment on mutual funds to help investors to make sound investment decisions. Ratings or rankings from these agencies are based on comprehensive analysis of relevant quantitative and qualitative information and are valued by investors. For example, Del Guercio and Tkac [10] find that Morningstar rating changes (rather than the changes in underlying performance measures) have substantial independent influence on the investment allocation decisions (cash inflows or outflows) of retail mutual fund investors.

\section{Related Literature}

The literature related to our paper may be divided into two main strands. First, there is a considerable body of work that has focused on the adverse selection problem in a money management context. For instance, Bhattacharya and Pfleiderer [11] first investigated the incentive contracts that can distinguish the types of managers and make the managers reveal their skill and private information in truth. Huberman and Kandel [12] and Huddart [13] develop models in which fund managers confront a given flat fee and show that managers use portfolio choices to signal their abilities. They find that the adverse selection problem significantly affects managers' investing behavior and the equilibrium results. Similarly, Das and Sundaram [14] contrast the "fulcrum" and the "incentive" types of fee contracts as incentive and signaling device. Stein [15] argues that the reason for the prevalence of open-end funds is that such funds could provide a natural signaling avenue for skilled managers in adverse selection problem. Gervais and Strobl [16] construct and analyze a model of adverse selection problem in delegated portfolio management where money managers reveal their skills via their choice of transparency for their fund. Huang et al. [17] constructs a new proxy for information asymmetry based on the principal component analysis by drawing on the market microstructure and the index of information asymmetry of managers and investors.

A second strand of research explores the cost and benefit of disclosure and transparency of funds and extends to the effect of regulation in general. Many of such studies focus on the hedge fund industry since it traditionally has less regulation or monitoring than the mutual fund industry. The subject of our paper, the value of external monitoring or, more generally, getting additional information on the quality of funds beyond past returns, does not distinguish the two industries so that the results can apply to both. Brown et al. [18] find mixed evidence on the value of mandatory disclosure for hedge funds and suggest that any consideration of disclosure requirement should take into account the endogenous nature of information production within the industry. Aggarwal and Jorion [19] find no evidence that a willingness to offer private transparency harms fund returns and no support for concerns that managers offering transparency suffer from selection bias. Coates IV and Hubbard [20] argue against regulation on mutual fund fees by presenting that competition exerts strong disciplinary force on funds. From a legal perspective Palmiter [21] argues that mutual fund boards perform poorly as "watchdog" supervisors of the management firms. Our paper complements this group of research and provides theoretical support for the value of external monitoring. By recognizing the endogenous nature of information disclosed by mutual fund or hedge fund industry, we want to show that additional information from external sources can help to improve contracting efficiency and alleviate the adverse selection problem.

\section{The Model}

The basic setup of the model is similar to that in Gervais et al. [9]. We study a two-period economy, each of which is populated with a different group of $n$ small risk-neutral investors and a risk-neutral fund manager. The fund manager (or just manager for short) has no wealth but may have some investment skills. Investors are wealthy, but have no investment skills. The investors, each with a dollar, must decide whether to invest in the market directly or to trust the manager with their money at the beginning of every period $i \in\{1,2\}$. The manager comes in two different types, 
skilled or unskilled, corresponding to her ability to generate investment profits. More precisely, the manager's type $\tilde{a}$, which is unknown for both investors and the manager herself at the outset, is drawn from the following distribution:

$$
\widetilde{a}= \begin{cases}a, & \operatorname{Pr} \phi, \\ 0, & \operatorname{Pr} 1-\phi,\end{cases}
$$

where $\phi \in[0,1]$ represents the probability that the manager is skilled and $a \in(0,1)$ represents the manager's professional ability. If the investors choose to invest in the financial market directly without hiring a manager, they will receive a perperiod return of $\widetilde{v}_{i}$. Assume $\widetilde{v}_{i}=x \in(0,1]$ or $\widetilde{v}_{i}=-x$ with equal probability. Thus the expected return to the unskilled investors, under the above assumption, is zero.

If instead investors delegate the investment decisionmaking power to the manager, the distribution of the traded financial assets' return is

$$
\widetilde{v}_{i}(\widetilde{a})=\left\{\begin{array}{lc}
+x, & \operatorname{Pr} \frac{1+\tilde{a}}{2}, \\
-x, & \operatorname{Pr} \frac{1-\tilde{a}}{2} .
\end{array}\right.
$$

That is, on average, the skilled manager could generate an excess return of $((1+a) / 2) x+((1-a) / 2)(-x)=a x>0$. In contrast, the unskilled manager cannot generate any excess returns, so investors do not benefit from her investment service.

Similar to Gervais et al. [9], we assume the cost of managing the fund is $k>0$, which is evenly shared among the investors. In period $i$, a manager with total investment of $N$ dollars, will generate net profit of $N \widetilde{v}_{i}-k$, and the expected surplus of the fund is $N a x \phi-k$ in the case that the manager is skilled with probability $\phi$.

The information about the manager's type is symmetric at the outset. Specifically, we assume that at the start of the first period, the manager is skilled with probability $\phi$. Both the investors and the money manager know it. This information is symmetric in the sense that the money manager possesses no better information about her own skills before the game starts. However, at the beginning of the second period, there will be information asymmetry between the investors and the manager. Investors update $\phi$ with the manager's firstperiod performance, but the manager updates $\phi$ with what she has privately learned about her ability in the first period investment. To simplify the analysis, we assume that the manager's private information tells her exactly her type, that is, for the manager herself, $\phi$ is either 0 or 1 after the first period (our results are unaffected if we assume more generally that the manager learns strictly more than the investors about her skill).

At the beginning of each period $i$, the manager announces her compensation contract $\widetilde{w}_{i}$. Based on this contract, on rational updates about the manager's skill and on the fund's realized return, investors can decide whether to accept the offer in this period. For simplicity, we assume that the contract always makes investors indifferent between investing in the fund and not investing. In other words, in the equilibrium investors make zero expected profit and managers capture the entire economic surplus that they generate (Berk and Green [22] and Gervais and Strobl [16] make the same assumption to simplify the model). Following Innes [23] and Rajan and Srivastava [24], we suppose that the manager has limited liability in the principal-agent relationship, that is, her compensation will never be negative. We assume $\phi \geq k / N a x$ to insure that the manager's income is nonnegative. Without loss of generality, we assume that the manager has no outside options and her reservation utility is zero (we could get the same result by assuming that the manager's reservation utility is a number other than zero).

\section{Equilibrium in the Absence of Monitoring}

To study the impact of external monitor on performancebased mutual fund incentives, we first refer to the benchmark case studied by Gervais et al. [9], to measure the lost surplus at the equilibrium without external monitoring.

4.1. First-Best Scenario. In the social optimal scenario, the investors and the manager have complete information about the manager's skills at the start of period one, and the fund's expected return is $\operatorname{Nax} \phi-k$. We now turn our attention to the second period.

If the investors could learn the manager's skill to the same extent as the manager herself does after the first period, they would only hire the skilled manager. The ex ante probability of this happening is $\phi$, and the expected net profit generated by a skilled manager is $N a x-k$. In the first-best scenario, the expected compensation of the manager, or the expected excess return of the investment, is $\phi(\mathrm{Nax}-k)$ in the second period.

Next we show that if investors cannot learn about managerial skills as much as the manager herself can, there will be value destruction in the economy.

4.2. Lost Surplus. The first-best outcome maximizes the income of the investment to the manager. To achieve it, investors must obtain the precise information about managerial skills as the manager herself. However, in reality, secondperiod investors can only update their beliefs about the managerial skills conditional on first-period return. For now, we concentrate on how this information asymmetry between investors and the manager affects the expected surplus of the fund.

Our first concern is the second-period investors' assessment about the manager's ability. Using Bayes' rule, it can be shown that if $\widetilde{v}_{1}=+x$, investors whose initial belief is probability $\phi$ will update the probability of the manager being skilled to

$$
\begin{aligned}
\phi_{+x} & \equiv \operatorname{Pr}\left(\widetilde{a}=a \mid \widetilde{v}_{1}=+x\right) \\
& =\frac{\operatorname{Pr}\left(\widetilde{v}_{1}=+x \mid \tilde{a}=a\right) \operatorname{Pr}(\widetilde{a}=a)}{\sum_{A \in\{a, 0\}} \operatorname{Pr}\left(\widetilde{v}_{1}=+x \mid \tilde{a}=A\right) \operatorname{Pr}(\widetilde{a}=A)} \\
& =\frac{((1+a) / 2) \phi}{((1+a) / 2) \phi+(1 / 2)(1-\phi)}=\frac{(1+a) \phi}{1+a \phi} .
\end{aligned}
$$


If $\widetilde{v}_{1}=-x$, investors will update their beliefs about the managerial skill to

$$
\begin{aligned}
\phi_{-x} & \equiv \operatorname{Pr}\left(\widetilde{a}=a \mid \widetilde{v}_{1}=-x\right) \\
& =\frac{\operatorname{Pr}\left(\widetilde{v}_{1}=-x \mid \tilde{a}=a\right) \operatorname{Pr}(\widetilde{a}=a)}{\sum_{A \in\{a, 0\}} \operatorname{Pr}\left(\widetilde{v}_{1}=-x \mid \widetilde{a}=A\right) \operatorname{Pr}(\widetilde{a}=A)} \\
& =\frac{((1-a) / 2) \phi}{((1-a) / 2) \phi+(1 / 2)(1-\phi)}=\frac{(1-a) \phi}{1-a \phi} .
\end{aligned}
$$

By inspection of (3) and (4), it is evident that $\phi_{+x}>\phi>$ $\phi_{-x}$. This inequality reveals two main points. First, under the assumption $\phi \geq k / \operatorname{Nax}, \phi$ is high enough so that the manager is hired in period one. So the manager who makes $\widetilde{v}_{1}=+x$ is certainly rehired no matter whether she is skilled or unskilled but lucky. Second, as investors pool their money into the fund if and only if they believe that the probability of the manager being skilled is no less than $k / N a x$, there are two situations about the manager's fate when $\widetilde{v}_{1}=-x$ : being fired if $\phi_{-x}<$ $k /$ Nax even though she is skilled and being rehired if $\phi_{-x} \geq$ $k /$ Nax even though she is unskilled. It is obvious that there is distortion in investors' assessment about the managerial skill, which relies only on the manager's past trading performance.

Furthermore, we investigate the second-period lost surplus resulting from the adverse selection problem, which is given in Proposition 1.

Proposition 1 (Gervais et al. [9]). If $\phi_{-x}<k /$ Nax, the lost surplus resulting from the adverse selection problem between investors and the manager is

$$
\Delta_{1} \equiv \frac{\phi(1-a)}{2}(N a x-k)+\frac{1-\phi}{2} k .
$$

If $\phi_{-x} \geq k /$ Nax, the lost surplus resulting from the adverse selection problem between investors and the manager is

$$
\Delta_{2} \equiv(1-\phi) k
$$

The first part of Proposition 1 shows that if investors update their belief about managerial skill only based on the manager's past performance and $\phi_{-x}<k / N a x$, the manager is retained if and only if she generates good first-period performance. In the first part of $(5), \phi(1-a) / 2$ shows the probability of a skilled manager messing up the first-period investment, and Nax $-k$ shows the value created by a skilled manager. The product of the two terms denotes the value destruction by giving up a skilled manager as a result of investors' asymmetric learning. Similarly, in the second part of $(5),(1-\phi) / 2$ shows the probability of an unskilled manager generating a good performance luckily and $k$ shows the costs carried on by investors if reinvested. Accordingly, the product of these two terms denotes the value destruction via retaining an unskilled manager due to investors' asymmetric learning.

The second part of Proposition 1 shows that if investors do not know the manager's type and $\phi_{-x} \geq k / N a x$, the manager will be rehired no matter what past performance she has generated. In (6), $1-\phi$ is the prior probability that the manager is unskilled; hence $(1-\phi) k$ denotes the value destruction via retaining an unskilled manager under this condition.

As argued by Gervais et al. [9], Proposition 1 shows that the surplus lost is the result of abandoning skilled managers and retaining unskilled managers. The intuition behind this result is that, without any monitoring, there is inefficient contracting that leads to value destruction in mutual funds if investors only learn from the fund's realized returns. Gervais et al. [9] investigate fund family overseeing multiple managers as a delegated monitor to reduce the inefficiency cost associated with adverse selection. In what follows, we will use an alternative mechanism by introducing an external monitor, to reveal more information about the manager's skills to investors and reduce welfare loss.

\section{The Role of External Monitoring}

In this section we analyze the effects of external monitoring on the dynamic behavior in mutual funds and the equilibrium outcome in the economy. In particular, we are interested in how external monitoring affects the performance-based contracting and the surplus of the investment.

5.1. Definitions. External monitoring can play a supervisory role via setting qualifications and behavior standards for fund managers, mandating the manager to disclose portfolio information, collecting information beyond past returns, and conducting analysis of fund quality. Investors benefit from the external monitoring mechanism by gaining more information about the manager (to simplify the model, we assume that signals sent by the external monitor are free. In the real world, information from government agencies is usually free, but information from the corporate world (e.g., Morningstar and Lipper) usually charges a fee. However, introducing a fixed monitoring cost will not change our results qualitatively). The underlying assumption is that the stronger the force of external monitoring is, the better the investors can learn about the manager's ability in fund management. In other words, the information beyond past fund returns allows investors to make investment decisions with greater accuracy and confidence whether a manager's performance is due to her ability or luck.

In addition to the basic model setup, we will show that an external monitor can help investors to identify the unskilled manager. More precisely, suppose that when investors make investment decisions before the start of the second period they observe a signal $\widetilde{s}_{m} \in\{0,1\}$, which has the following distribution:

$$
\begin{aligned}
& \operatorname{Pr}\left(\widetilde{s}_{m}=1 \mid \tilde{a}=a\right)=1, \\
& \operatorname{Pr}\left(\widetilde{s}_{m}=0 \mid \tilde{a}=0\right)=m=1-\operatorname{Pr}\left(\widetilde{s}_{m}=1 \mid \tilde{a}=0\right) .
\end{aligned}
$$

A bigger $m$ implies that the signal $\widetilde{s}_{m}$ tells investors more accurately about the manager's type. Therefore, $m \in(0,1)$ can be understood as the strength of external monitoring. A signal $\widetilde{s}_{m}=0$ makes it distinct to investors that the manager's type is unskilled and that they should not hire her, as such a signal can never be observed when the manager's type is 
skilled. However, investors do not always receive such a signal when the manager is unskilled; they receive such a signal with a probability $m$. On the other hand, when $\widetilde{s}_{m}=1$ the manager can be skilled or unskilled, but such a signal can reduce the probability of an unskilled manager being hired since

$$
\begin{aligned}
\operatorname{Pr} & \left(\widetilde{a}=0 \mid \widetilde{s}_{m}=1\right) \\
& =\frac{\operatorname{Pr}\left(\widetilde{s}_{m}=1 \mid \widetilde{a}=0\right) \operatorname{Pr}(\widetilde{a}=0)}{\sum_{A \in\{a, 0\}} \operatorname{Pr}\left(\widetilde{s}_{m}=1 \mid \tilde{a}=A\right) \operatorname{Pr}(\widetilde{a}=A)} \\
& =\frac{(1-m)(1-\phi)}{\phi+(1-m)(1-\phi)}
\end{aligned}
$$

is decreasing in $m$.

5.2. Surplus under External Monitoring. With the definition of external monitoring outlined above, investors update their beliefs about the managerial skill according to the signal $\widetilde{s}_{m}$ and the manager's realized return. If investors observe $\widetilde{s}_{m}=$ 0 , the manager will be fired undoubtedly. If instead investors observe $\widetilde{s}_{m}=1$, using Bayes' rule, investors will update their second-period assessment according to the following lemma.

Lemma 2. Under external monitoring, after first-period returns of $+x$, investors' assessment about the manager's skill conditional on $\widetilde{s}_{m}=1$ is

$$
\phi_{+x}^{M} \equiv \frac{(1+a) \phi}{(1+a) \phi+(1-m)(1-\phi)} .
$$

After first-period returns of $-x$, investors' assessment about the manager's skill conditional on $\widetilde{s}_{m}=1$ is

$$
\phi_{-x}^{M} \equiv \frac{(1-a) \phi}{(1-a) \phi+(1-m)(1-\phi)},
$$

where the superscript " $M$ " refers to the fact that an external monitor exists.

Since $\phi_{+x}^{M}-\phi=(1-\phi)(a+m) \geq 0$ and $\phi_{-x}^{M}-\phi=$ $(1-\phi)(m-a)$, the manager who makes $\widetilde{v}_{1}=+x$ is certainly rehired no matter whether she is skilled, conditional on the signal $\widetilde{s}_{m}=1$ being observed by investors. However, it is uncertain which probability is higher between $\phi_{-x}^{M}$ and $\phi$. So when the manager makes $\widetilde{v}_{1}=-x$ and the signal received was $\widetilde{s}_{m}=1$, she will be fired if $\phi_{-x}^{M}<k /$ Nax even though she is skilled and will be rehired if $\phi_{-x}^{M} \geq k /$ Nax even though she is unskilled. In comparison with the baseline case without external monitoring as stated in Proposition 1, the following proposition shows the second-period lost surplus under external monitoring.

Proposition 3. If $\phi_{-x}^{M}<k / N a x$, the lost surplus resulting from the adverse selection problem under external monitoring is

$$
\Delta_{1}^{M} \equiv \frac{\phi(1-a)}{2}(N a x-k)+\frac{1-\phi}{2} k(1-m) .
$$

If $\phi_{-x}^{M} \geq k /$ Nax, the lost surplus resulting from the adverse selection problem under external monitoring is

$$
\Delta_{2}^{M} \equiv(1-\phi) k(1-m) .
$$

By inspection of Proposition 3, we realize that the lost surplus decreases with $m$ in both cases, which implies that external monitoring contributes to expected value by relieving the information asymmetry between investors and the manager. This result is consistent with Gervais et al. [9], who investigate fund families as delegated monitors and argue that monitoring by a mutual fund family can credibly reveal information about manager quality to investors and thus reduce efficiency loss. Previous research by Diamond [25] and Krasa and Villamil [26] also find that the pooling of monitor mechanism can improve the efficiency in principalagent problems. The derivation of Proposition 3 delivers the insight of Proposition 4 immediately.

Proposition 4. As external monitoring strengthens $(m \rightarrow 1)$, the efficiency loss resulting from the adverse selection problem converges to zero.

This result can be interpreted from two aspects. On one hand, as we can see in (10), $\phi_{-x}^{M}$ is increasing in the strength of external monitoring $m$. As external monitoring becomes stricter (i.e., better quality of the signal), investors are inclined to believe that the manager is skilled even though her past performance is unsatisfactory conditional on $\widetilde{s}_{m}=1$. So the expected loss from dismissing skilled managers is reduced. On the other hand, it is not difficult to understand that the probability of retaining an unskilled manager will be reduced as $m$ increases. In the limit, this proposition shows that the entire contracting inefficiency is eliminated through external monitoring. If the external monitor acts as a validation mechanism that could identify the manager's type accurately (i.e., $m=1$ ), then the monitoring mechanism can create value through helping investors retain only the skilled managers.

In practice, external monitors acquire more information from the fund managers and have better analyzing skills to derive the actual ability of the fund managers. This process may take several periods. As a result, the signals received by investors from the external monitor will also become more accurate over time. Readers can interpret the result in Proposition 4 as a limiting case. If we allow both the investors and the external monitor to update their beliefs over time, the model will become much complicated and intractable. However, under such circumstances, as long as the realized probability distribution for the external monitor first-order stochastically dominates that of the investors, the existence of external monitoring should still be welfare improving.

\section{Conclusion}

Within a dynamical economic framework this paper addresses contracting inefficiency when investors base their delegation decision solely on the return history of managers. We show how the surplus loss due to contracting inefficiency can be recovered by external monitoring for mutual funds. In 
particular, we assume that external monitoring can provide investors with relevant information about the manager's ability, by setting qualifications and behavior standards for fund managers, mandating appropriate disclosure of certain portfolio information, and providing assessment of fund value and quality. We find that external monitoring mechanism adds value by narrowing the information asymmetry between investors and the manager, and the contracting efficiency converges to first-best as external monitoring strengthens in the dynamical system. These results provide strong theoretical ground for the important role played by supervising mechanism in delegated portfolio management.

Although the analysis in this paper is conducted in the context of the mutual fund industry, the results regarding the value of monitoring are equally relevant to other forms of delegated investments such as hedge funds. Since the global financial crisis in 2008 regulations on the hedge fund industry have been significantly strengthened, a reform supported by the theoretical results in this paper.

This paper focuses on the value of external monitoring on contracting efficiency and lost surplus due to adverse selection, but we should keep in mind that in the investment world some factors such as compliance cost and proprietary information would influence the effect of monitoring. Thus an appropriate level of monitoring that balances its cost and benefit would be the optimal policy. Direct empirical evidence on the value of monitoring or regulation is rare and has provided mixed results (Aggarwal and Jorion [19]; Aragon et al. [27]), but there has been some encouraging finding that is consistent with our proposal. For example, Gregory-Allen and Thompson [28] find that in Australia and New Zealand fund returns are not harmed by disclosure and flow to disclosing funds is higher.

Future research may investigate the optimal contracts under the supervision of external monitoring in mutual funds. The adverse selection problem under the influence of irrational bias or investor sentiment in portfolio management is also worth further exploration (Huang et al. [29]).

\section{Appendix}

\section{A. Proof of Proposition 1}

Assume that $W$ is the manager's expected second-period compensation at the outset. If $\phi_{-x}<k / \operatorname{Nax}$, the manager is rehired if and only if $\widetilde{v}_{1}=+x$. This outcome has a probability of occurrence of $(1+a \phi) / 2$, and the manager's compensation conditional on $\widetilde{v}_{1}=+x$ is $\operatorname{Nax}[(1+a) \phi /(1+a \phi)]-k$. So we get

$$
\begin{aligned}
W_{1}= & \frac{1+a \phi}{2}\left\{\operatorname{Nax}\left[\frac{(1+a) \phi}{1+a \phi}\right]-k\right\} \\
= & \phi(N a x-k) \\
& -\left[\frac{\phi(1-a)}{2}(\operatorname{Nax}-k)+\frac{1-\phi}{2} k\right] .
\end{aligned}
$$

The first part of (A.1) is the expected value creation in the first-best scenario, and the deduction part of (A.1) is the expected value destruction in second-period contracts, which arrives at (5).

If $\phi_{-x} \geq k / N a x$, the manager is rehired regardless of her first-period performance. Then the manager's expected second-period compensation is the same as her first-period compensation; that is,

$$
W_{2}=N a x \phi-k=\phi(N a x-k)-(1-\phi) k .
$$

Likewise, the deduction part of (A.2) is the expected value destruction in second-period contracts, which arrives at (6).

\section{B. Proof of Lemma 2}

Using Bayes' rule, we have

$$
\begin{aligned}
& \phi_{+x}^{M} \equiv \operatorname{Pr}\left(\widetilde{a}=a \mid \widetilde{v}_{1}=+x, \widetilde{s}_{m}=1\right) \\
& =\frac{\operatorname{Pr}\left(\widetilde{v}_{1}=+x \mid \tilde{a}=a, \widetilde{s}_{m}=1\right) \operatorname{Pr}\left(\widetilde{a}=a \mid \widetilde{s}_{m}=1\right)}{\sum_{A \in\{a, 0\}} \operatorname{Pr}\left(\widetilde{v}_{1}=+x \mid \tilde{a}=A, \widetilde{s}_{m}=1\right) \operatorname{Pr}\left(\widetilde{a}=A \mid \widetilde{s}_{m}=1\right)},
\end{aligned}
$$

and from (8)

$$
\begin{aligned}
\operatorname{Pr}\left(\widetilde{a}=a \mid \widetilde{s}_{m}=1\right) & =1-\frac{(1-m)(1-\phi)}{\phi+(1-m)(1-\phi)} \\
& =\frac{\phi}{\phi+(1-m)(1-\phi)} ;
\end{aligned}
$$

then we can get

$$
\phi_{+x}^{M}=\frac{((1+a) / 2)(\phi /(\phi+(1-m)(1-\phi)))}{((1+a) / 2)(\phi /(\phi+(1-m)(1-\phi)))+(1 / 2)[1-\phi /(\phi+(1-m)(1-\phi))]}=\frac{(1+a) \phi}{(1+a) \phi+(1-m)(1-\phi)}
$$

Likewise

$$
\begin{aligned}
\phi_{-x}^{M} & \equiv \operatorname{Pr}\left(\widetilde{a}=a \mid \widetilde{v}_{1}=-x, \widetilde{s}_{m}=1\right)=\frac{\operatorname{Pr}\left(\widetilde{v}_{1}=-x \mid \tilde{a}=a, \widetilde{s}_{m}=1\right) \operatorname{Pr}\left(\tilde{a}=a \mid \widetilde{s}_{m}=1\right)}{\sum_{A \in\{a, 0\}} \operatorname{Pr}\left(\widetilde{v}_{1}=-x \mid \widetilde{a}=A, \widetilde{s}_{m}=1\right) \operatorname{Pr}\left(\widetilde{a}=A \mid \widetilde{s}_{m}=1\right)} \\
& =\frac{((1-a) / 2)(\phi /(\phi+(1-m)(1-\phi)))}{((1-a) / 2)(\phi /(\phi+(1-m)(1-\phi)))+(1 / 2)[1-\phi /(\phi+(1-m)(1-\phi))]}=\frac{(1-a) \phi}{(1-a) \phi+(1-m)(1-\phi)}
\end{aligned}
$$




\section{Proof of Proposition 3}

Under external monitoring, if $\phi_{-x}^{M}<k / \mathrm{Nax}$, the manager is rehired if and only if $\widetilde{v}_{1}=+x$. This outcome has a probability of occurrence of $((1+a) \phi+(1-m)(1-\phi)) / 2$, and from (9) the manager's compensation conditional on $\widetilde{v}_{1}=+x$ is $\operatorname{Nax}[(1+$ a) $\phi /((1+a) \phi+(1-m)(1-\phi))]-k$. So we get

$$
\begin{aligned}
W_{1}^{M} & =\frac{(1+a) \phi+(1-m)(1-\phi)}{2}\left\{N a x\left[\frac{(1+a) \phi}{(1+a) \phi+(1-m)(1-\phi)}\right]-k\right\} \\
& =\phi(N a x-k)-\left[\frac{\phi(1-a)}{2}(N a x-k)+\frac{1-\phi}{2} k(1-m)\right] .
\end{aligned}
$$

The first part of (C.1) is the expected value creation in the first-best scenario, and the deduction part of (C.1) is the expected value destruction in second-period contracts under external monitoring, which arrives at (11).

If $\phi_{-x}^{M} \geq k /$ Nax, the manager is rehired so long as investors observe $\widetilde{s}_{m}=1$. Then when $\widetilde{v}_{1}=+x$ under this condition, the manager's compensation is $\operatorname{Nax}[(1+a) \phi /((1+$ a) $\phi+(1-m)(1-\phi))]-k$, and this outcome has a probability of occurrence of $((1+a) \phi+(1-m)(1-\phi)) / 2$. When $\widetilde{v}_{1}=-x$ conditional on $\widetilde{s}_{m}=1$, from (10), the manager's compensation is $\operatorname{Nax}[(1-a) \phi /((1-a) \phi+(1-m)(1-\phi))]-k$, and this outcome has a probability of occurrence of $((1-a) \phi+(1-m)(1-\phi)) / 2$. So we get

$$
\begin{aligned}
W_{2}^{M}= & \frac{(1+a) \phi+(1-m)(1-\phi)}{2}\left\{\operatorname{Nax}\left[\frac{(1+a) \phi}{(1+a) \phi+(1-m)(1-\phi)}\right]-k\right\} \\
& +\frac{(1-a) \phi+(1-m)(1-\phi)}{2}\left\{\operatorname{Nax}\left[\frac{(1-a) \phi}{(1-a) \phi+(1-m)(1-\phi)}\right]-k\right\}=\phi(N a x-k)-(1-\phi) k(1-m) .
\end{aligned}
$$

Likewise, the deduction part of (C.2) is the expected value destruction in second-period contracts, which arrives at (12).

\section{Proof of Proposition 4}

When $m \rightarrow 1$, we can get $\phi_{-x}^{M} \geq \phi \geq k /$ Nax as $\phi_{-x}^{M}-\phi=$ $(1-\phi)(m-a)$. So from Proposition 3 , the lost surplus is $(1-$ $\phi) k(1-m)$, which becomes zero when $m \rightarrow 1$.

\section{Competing Interests}

The authors declare that they have no competing interests.

\section{Acknowledgments}

The authors appreciate the comments by two reviewers. This study is supported by the National Natural Science Foundation of China (nos. 71101024, 71571038, 71171042, 71161013, and 71561011), the Social Science Foundation of Ministry of Education of China (no. 10YJC630203), the Fundamental Research Funds for the Central Universities in China (no. N150602001), the General Science Foundation of Department of Education of Liaoning Province (no. W2012039), and China Postdoctoral Science Foundation (no. 2012M511450). Science and Technology Project of Jiangxi Provincial Education Department (no. GJJ14323) and financial supports from Jiangxi Postdoctoral Science Foundation of China (2012) are gratefully acknowledged.

\section{References}

[1] R. A. Ippolito, "Efficiency with costly information: a study of mutual fund performance, 1965-1984," The Quarterly Journal of Economics, vol. 104, no. 1, pp. 1-23, 1989.

[2] J. Chevalier and G. Ellison, "Risk taking by mutual funds as a response to incentives," Journal of Political Economy, vol. 105, no. 6, pp. 1167-1200, 1997.

[3] E. R. Sirri and P. Tufano, "Costly search and mutual fund flows," The Journal of Finance, vol. 53, no. 5, pp. 1589-1622, 1998.

[4] D. Del Guercio and P. A. Tkac, "The determinants of the flow of funds of managed portfolios: mutual funds vs. pension funds," Journal of Financial and Quantitative Analysis, vol. 37, no. 4, pp. 523-557, 2002.

[5] K. Daniel, M. Grinblatt, S. Titman, and R. Wermers, "Measuring mutual fund performance with characteristic-based benchmarks," Journal of Finance, vol. 52, no. 3, pp. 1035-1058, 1997.

[6] E. J. Elton, M. J. Gruber, S. Das, and M. Hlavka, "Efficiency with costly information: a reinterpretation of evidence from managed portfolios," Review of Financial Studies, vol. 6, no. 1, pp. 1-22, 1993.

[7] E. J. Elton, M. J. Gruber, and C. R. Blake, "Survivorship bias and mutual fund performance," Review of Financial Studies, vol. 9, no. 4, pp. 1097-1120, 1996.

[8] M. J. Gruber, "Another puzzle: the growth in actively managed mutual funds," Journal of Finance, vol. 51, no. 3, pp. 783-810, 1996.

[9] S. Gervais, A. W. Lynch, and D. K. Musto, "Fund families as delegated monitors of money managers," Review of Financial Studies, vol. 18, no. 4, pp. 1139-1169, 2005. 
[10] D. D. Guercio and P. A. Tkac, "Star power: the effect of morningstar ratings on mutual fund flow," Journal of Financial and Quantitative Analysis, vol. 43, no. 4, pp. 907-936, 2008.

[11] S. Bhattacharya and P. Pfleiderer, "Delegated portfolio management," Journal of Economic Theory, vol. 36, no. 1, pp. 1-25, 1985.

[12] G. Huberman and S. Kandel, "On the incentives for money managers. A signalling approach," European Economic Review, vol. 37, no. 5, pp. 1065-1081, 1993.

[13] S. Huddart, "Reputation and performance fee effects on portfolio choice by investment advisers," Journal of Financial Markets, vol. 2, no. 3, pp. 227-271, 1999.

[14] S. R. Das and R. K. Sundaram, "Fee speech: signaling, risksharing, and the impact of fee structures on investor welfare," Review of Financial Studies, vol. 15, no. 5, pp. 1465-1497, 2002.

[15] J. C. Stein, "Why are most funds open-end? Competition and the limits of arbitrage," Quarterly Journal of Economics, vol. 120, no. 1, pp. 247-272, 2005.

[16] S. Gervais and G. Strobl, "The industrial organization of money management," Working Paper, 2012, http://ssrn.com/abstract= 2023884.

[17] C. Huang, X. Ma, and Q. Lan, "An empirical study on listed company's value of cash holdings: an information asymmetry perspective," Discrete Dynamics in Nature and Society, vol. 2014, Article ID 897278, 12 pages, 2014.

[18] S. Brown, W. Goetzmann, B. Liang, and C. Schwarz, "Mandatory disclosure and operational risk: evidence from hedge fund registration," Journal of Finance, vol. 63, no. 6, pp. 2785-2815, 2008.

[19] R. K. Aggarwal and P. Jorion, "Is there a cost to transparency?," Financial Analysts Journal, vol. 68, no. 2, pp. 108-123, 2012.

[20] J. C. Coates IV and R. G. Hubbard, "Competition in the mutual fund industry: evidence and implications for policy," Journal of Corporation Law, vol. 33, no. 1, pp. 151-222, 2007.

[21] A. R. Palmiter, "Mutual fund boards: a failed experiment in regulatory outsourcing," Financial \& Commercial Law, vol. 1, pp. 165-208, 2006.

[22] J. B. Berk and R. C. Green, "Mutual fund flows and performance in rational markets," Journal of Political Economy, vol. 112, no. 6, pp. 1269-1295, 2004.

[23] R. D. Innes, "Limited liability and incentive contracting with exante action choices," Journal of Economic Theory, vol. 52, no. 1, pp. 45-67, 1990.

[24] U. Rajan and S. Srivastava, "Portfolio delegation with limited liability," Working paper, SSRN, 2003, http://ssrn.com/abstract= 241838.

[25] D. W. Diamond, "Financial intermediation and delegated monitoring," The Review of Economic Studies, vol. 51, no. 3, pp. 393414, 1984.

[26] S. Krasa and A. P. Villamil, "Monitoring the monitor: an incentive structure for a financial intermediary," Journal of Economic Theory, vol. 57, no. 1, pp. 197-221, 1992.

[27] G. O. Aragon, M. Hertzel, and Z. Shi, "Why do hedge funds avoid disclosure? Evidence from confidential 13F filings," Journal of Financial and Quantitative Analysis, vol. 48, no. 5, pp. 1499-1518, 2013.

[28] R. Gregory-Allen and K. Thompson, "Corporate Governance in mutual funds: the impact of holdings disclosure," Working Paper, Massey University, 2015.

[29] C. Huang, X. Yang, X. Yang, and H. Sheng, "An empirical study of the effect of investor sentiment on returns of different industries," Mathematical Problems in Engineering, vol. 2014, Article ID 545723, 11 pages, 2014. 


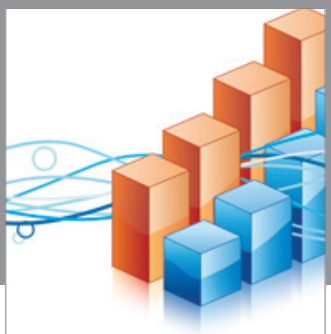

Advances in

Operations Research

vatem alat4

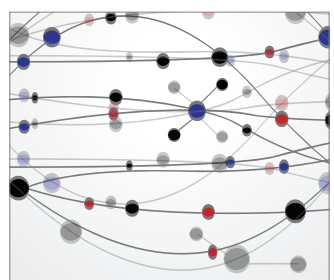

\section{The Scientific} World Journal
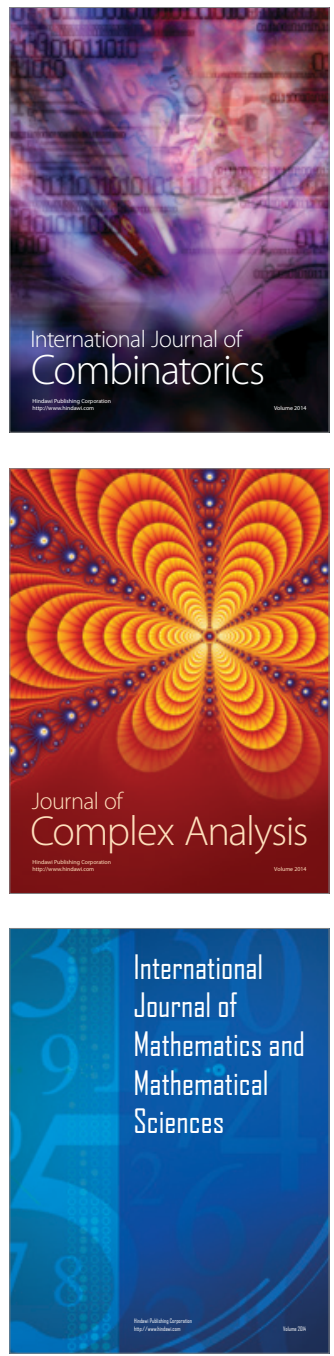
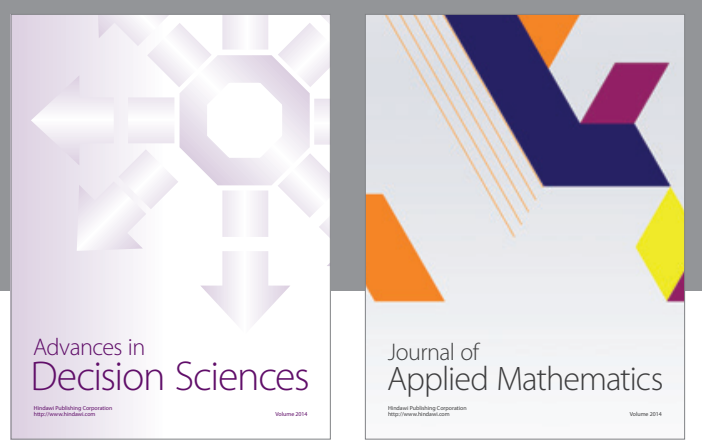

Algebra

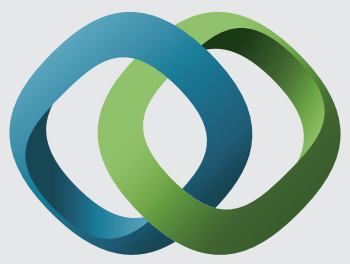

\section{Hindawi}

Submit your manuscripts at

http://www.hindawi.com
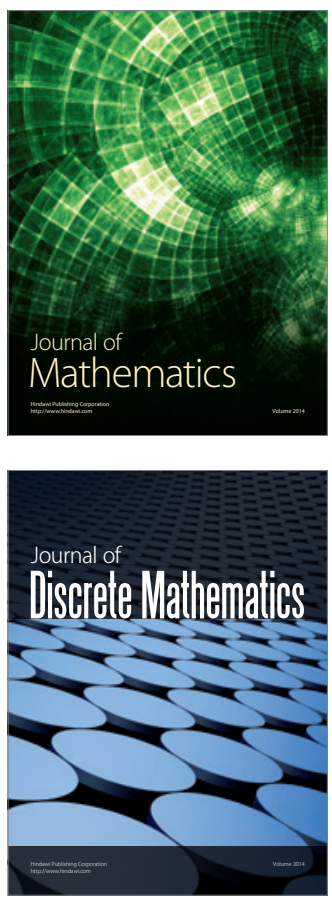

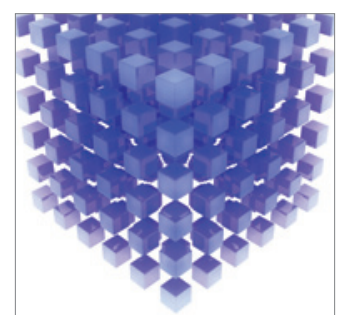

Mathematical Problems in Engineering
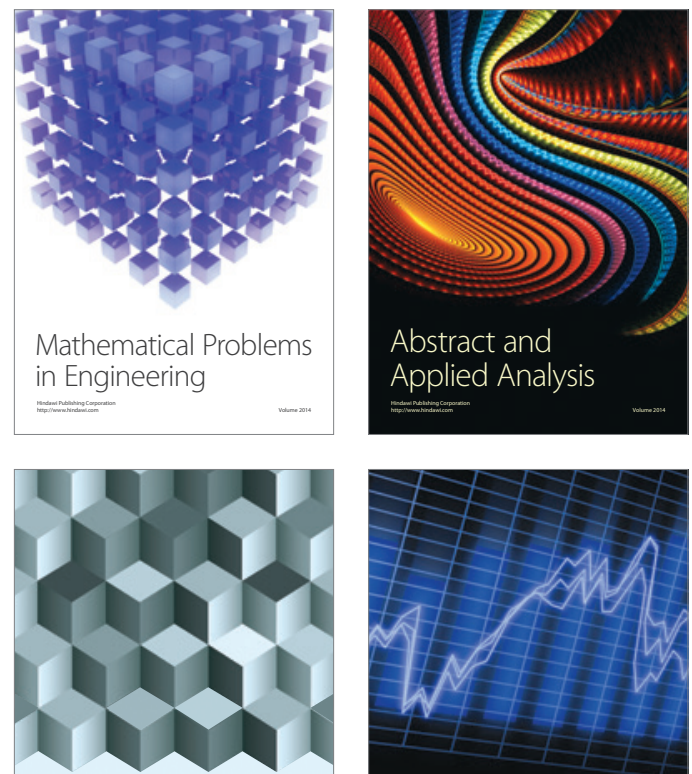

Journal of

Function Spaces

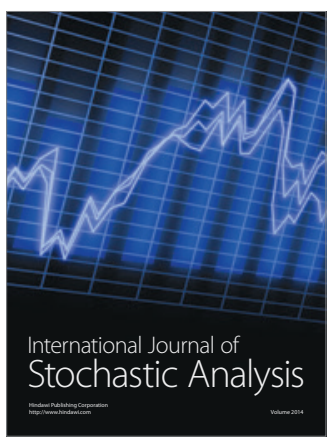

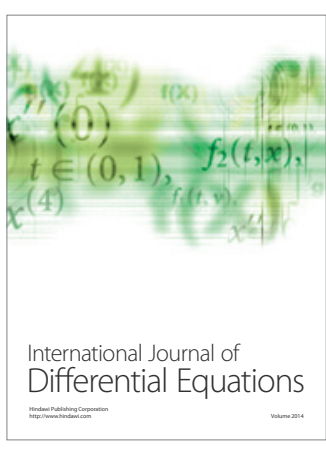
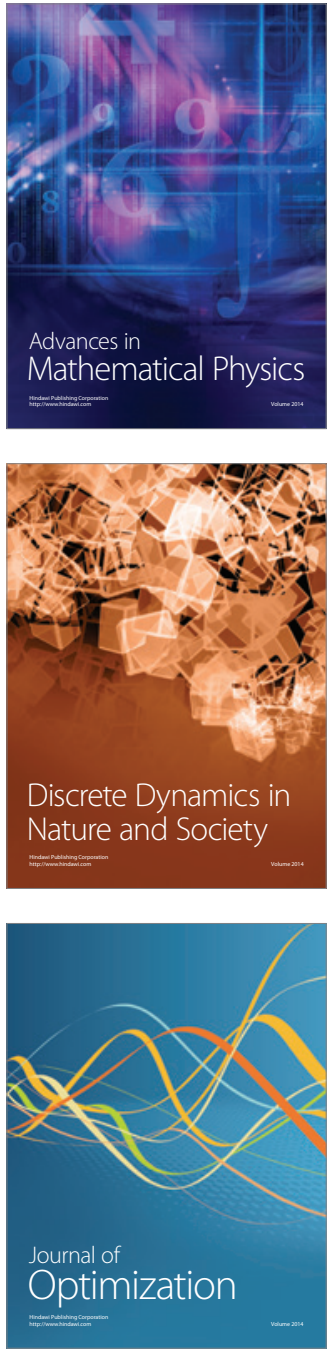